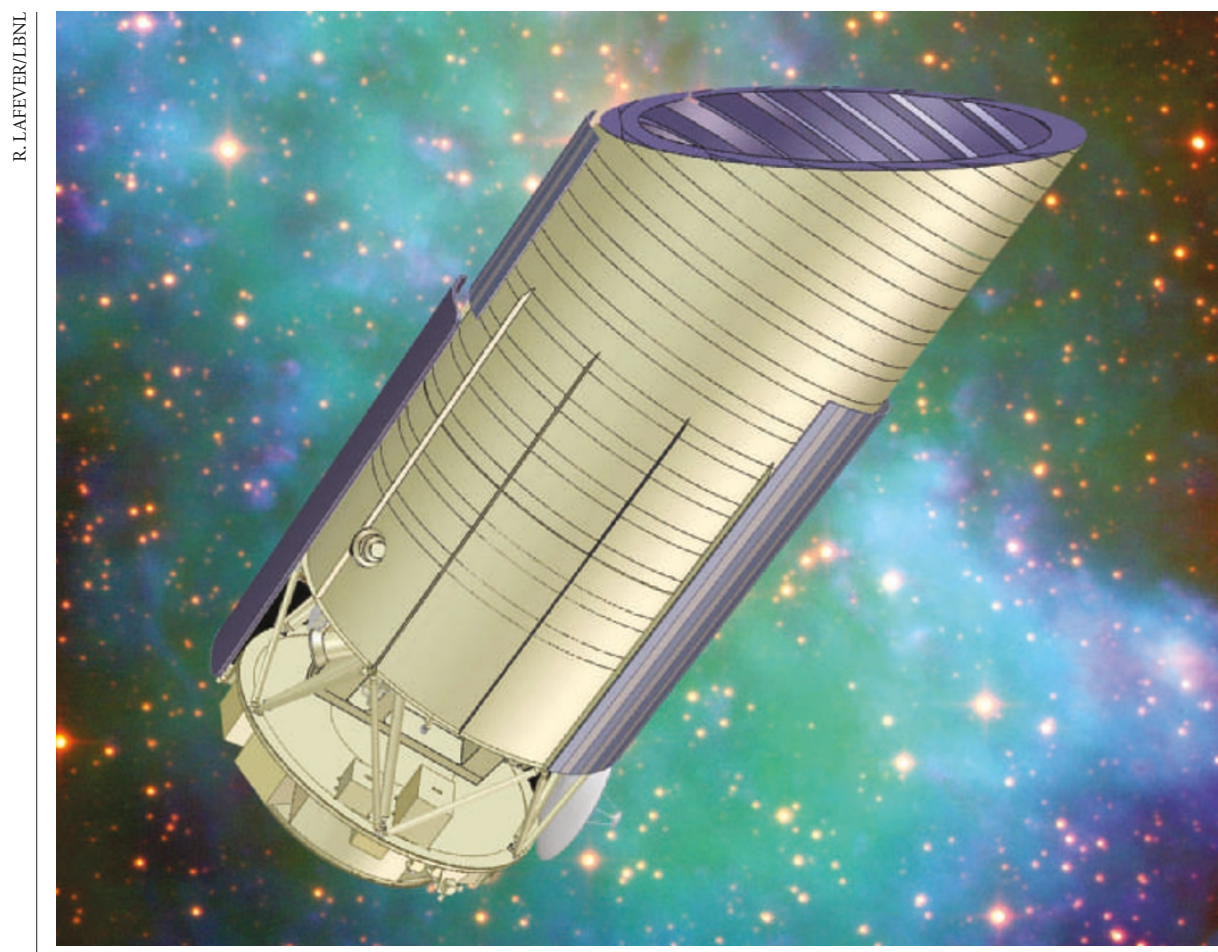

Under threat? Probes designed to investigate deep space, such as SNAP, face unexpected delays.

\title{
NASA casts a shadow over bid to illuminate dark energy
}

\section{Geoff Brumfiel, Washington}

NASA is delaying a mission to explore the fundamental make-up of the Universe, riling astronomers and physicists who consider it a top priority.

About three-quarters of all the mass and energy in the Universe may be dark energy. In a ground-breaking collaboration, NASA and the US Department of Energy (DOE) were set to explore this poorly understood entity on the Joint Dark Energy Mission, which supporters hoped would be launched into space by 2014 (see Nature 425, 887; 2003).

But the collaboration is now on hold, as NASA re-tools for possible manned flights to the Moon and Mars. Two other missions in NASA's 'Beyond Einstein' astrophysics programme - one designed to probe microwaves left over from the Big Bang and the other to search for black holes also failed to show up in NASA's five-year budget outlook, released on 2 February. Physicists had expected the missions to be in the plan if they were to be completed on the schedule that the space agency allocated to them last year.

The dark energy mission was listed as a top priority in a National Academy of Sciences study of interdisciplinary research in astronomy and physics, published in April 2002. "It's a serious casualty," says Roger Blandford, who heads the Kavli Institute for Particle Astrophysics and Cosmology at Stanford University in California.

The DOE remains committed to the project - at least for now. Saul Perlmutter, a cosmologist at Lawrence Berkeley National Laboratory in California, is the primary investigator for one proposed version of the mission - the supernova/acceleration probe, or SNAP. He says that he is disappointed by NASA's decision but adds that the research can progress without the space agency's involvement. Robin Staffin, director of the DOE's high-energy physics division, says the department will spend between $\$ 7$ million and \$8 million next year developing detectors for the mission.

But researchers acknowledge that it will ultimately require NASA's support to carry out a mission that is expected to cost about $\$ 900$ million.

NASA programme manager Paul Hertz downplayed the decision to omit it from the agency's five-year budget plan. "Nothing was cancelled," he says. "But the timeline has been stretched out." He says that the Office of Space Science, which had overseen the project, will continue to push for the mission to go ahead.

But Rocky Kolb, who was part of an independent NASA advisory board that originally recommended the mission, says it may prove a tough sell. "The immediate problem is that no one knows how to use dark energy to get to Mars," he quips.
Thumbs up for fresh formula to gauge university funding

Jim Giles, London

What's the best way to divide $\mathfrak{E} 8$ billion (US $\$ 15$ billion) in annual funding between Britain's 100-plus universities? A fresh approach to the challenge was revealed last week, and looks to have the qualified backing of academics and administrators.

The plan would revamp the Research Assessment Exercise, one of the world's most extensive attempts to measure the performance of university departments. The UK government uses the findings to allocate block grants that subsidize research and teaching at each university.

But the last assessment, in 2001, drew sharp criticism. So the plan would scrap its most contentious component - a seven-point ranking scale for every university department that tended to reward small variations in performance with big differences in funding.

In its place, the funding councils will draw up a more detailed profile of each department's output. Each piece of work submitted to the exercise, such as a published book or paper, will be awarded between zero and four stars, with the top two rankings corresponding to work of international significance. The profile will show what percentage of submissions achieved each ranking, and how many researchers entered work.

The councils say these profiles will provide a more subtle snapshot of performance, allowing money to be distributed more fairly. They also hope the profiles will help identify pockets of excellence in average departments something that was lost when scores were averaged to create the old rankings. "The true scale and strength of the best work will be more visible," says Howard Newby, chief executive of the Higher Education Funding Council for England.

University administrators have praised the councils for ditching some of the proposals made last May in an outside review of the assessment exercise (see Nature 423, 574; 2003). A proposal to allow less research-intensive institutes to go through a 'light-touch' assessment has not been taken up, nor has the idea of running interim evaluations between main assessments, which take place roughly once every six years.

But one gripe hasn't been resolved the funding councils have denied requests from universities to publish the formulae that link their profiles to the amount of money they get. 